\title{
Erratum to robotic lobectomy has the greatest benefit in patients with marginal pulmonary function
}

\author{
Monica Casiraghi ${ }^{1}$, Lorenzo Spaggiari ${ }^{1,2}$ \\ ${ }^{1}$ Division of Thoracic Surgery, IEO, European Institute of Oncology, IRCCS, Milan, Italy; ${ }^{2}$ Department of Oncology and Hemato-oncology, \\ University of Milan, Milan, Italy \\ Correspondence to: Dr. Monica Casiraghi. Division of Thoracic Surgery, IEO, European Institute of Oncology, Via G. Ripamonti, 43520141 Milan, \\ Italy. Email: monica.casiraghi@ieo.it.
}

doi: $10.21037 /$ jtd.2019.09.13

View this article at: http://dx.doi.org/10.21037/jtd.2019.09.13

Erratum to: J Thorac Dis 2019;11:S322-4.

Robotic lobectomy has the greatest benefit in patients with marginal pulmonary function

In the article that appeared on Page S322-S324, Vol 11, Suppl 3 (March 2019) Issue of the Fournal of Thoracic Disease (fTD) (1), an affiliation was mistakenly translated, and it should have read as follow: Division of Thoracic Surgery, IEO, European Institute of Oncology, IRCCS, Milan, Italy.

It has been corrected in this corrigendum. The authors would like to apologize for any inconvenience caused.

\section{References}

1. Casiraghi M, Spaggiari L. Robotic lobectomy has the greatest benefit in patients with marginal pulmonary function. J Thorac Dis 2019;11:S322-4.

Cite this article as: Casiraghi M, Spaggiari L. Erratum to robotic lobectomy has the greatest benefit in patients with marginal pulmonary function. J Thorac Dis 2019;11(9):E151. doi: $10.21037 /$ jtd.2019.09.13 